\title{
Head-of-Bed Elevation Improves End-Expiratory Lung Volumes in Mechanically Ventilated Subjects: A Prospective Observational Study
}

\author{
Amy J Spooner RN, Amanda Corley RN, Nicola A Sharpe RN, Adrian G Barnett PhD, \\ Lawrence R Caruana, Naomi E Hammond RN MN MPH, and \\ John F Fraser PhD MRCP FFARCSI FRCA FCICM
}

\begin{abstract}
BACKGROUND: Head-of-bed elevation (HOBE) has been shown to assist in reducing respiratory complications associated with mechanical ventilation; however, there is minimal research describing changes in end-expiratory lung volume. This study aims to investigate changes in end-expiratory lung volume in a supine position and 2 levels of HOBE. METHODS: Twenty postoperative cardiac surgery subjects were examined using electrical impedance tomography. End-expiratory lung impedance (EELI) was recorded as a surrogate measurement of end-expiratory lung volume in a supine position and at $20^{\circ}$ and then $30^{\circ}$. RESULTS: Significant increases in end-expiratory lung volume were seen at both $20^{\circ}$ and $30^{\circ} \mathrm{HOBE}$ in all lung regions, except the anterior, with the largest changes from baseline (supine) seen at $30^{\circ}$. From baseline to $30^{\circ} \mathrm{HOBE}$, global EELI increased by 1,327 impedance units $(95 \%$ CI $1,080-1,573, P<.001)$. EELI increased by 1,007 units $(95 \%$ CI $880-1,134, P<.001)$ in the left lung region and by 320 impedance units $(95 \%$ CI $188-451$, $P<.001)$ in the right lung. Posterior increases of 1,544 impedance units (95\% CI 1,405-1,682, $P<.001)$ were also seen. EELI decreased anteriorly, with the largest decreases occurring at $30^{\circ}$ ( -335 impedance units, $95 \%$ CI -486 to $-183, P<.001)$. CONCLUSIONS: HOBE significantly increases global and regional end-expiratory lung volume; therefore, unless contraindicated, all mechanically ventilated patients should be positioned with HOBE. Key words: end-expiratory lung volume; electrical impedance tomography; lung volume; mechanical ventilation; positioning; surgery. [Respir Care 2014;59(10):1583-1589. (C) 2014 Daedalus Enterprises]
\end{abstract}

\section{Introduction}

Although mechanical ventilation is a life-saving measure, it is associated with respiratory complications such as atelectasis, ventilator-induced lung injury, ventilator-associated pneumonia, and ARDS. ${ }^{1-3}$ This results in increased

The authors are affiliated with the Critical Care Research Group, Adult Intensive Care Services, The Prince Charles Hospital and University of Queensland, Chermside, Brisbane, Australia, with the exception of Dr Barnett, who is affiliated with the Institute of Health and Biomedical Innovation and School of Public Health and Social Work, Queensland University of Technology, Kelvin Grove, Brisbane, Australia.

Ms Corley and Dr Fraser received grant funding for this study from The Prince Charles Hospital Foundation. Dr Fraser was supported by a Health Research Fellowship from the Office of Health and Medical Research, Queensland Health. The other authors have disclosed no conflicts of interest. mechanical ventilation, prolonged stays in the ICU and hospital, and increased costs to the health care system. ${ }^{4,5}$

Head-of-bed elevation (HOBE) is one of several therapeutic interventions that have been demonstrated to reduce respiratory complications associated with mechanical ventilation. ${ }^{2,6,7}$ Although literature is available on the effects of various positions on oxygenation, hemodynamics, and prevalence of pulmonary complications, there are few studies that have examined lung volume in relation to HOBE. ${ }^{8-10}$

Until recently, methods to monitor changes in lung ventilation in the ICU have been limited and challenging. For

\footnotetext{
Correspondence: Amy J Spooner RN, Critical Care Research Group, Adult Intensive Care Services, The Prince Charles Hospital and University of Queensland, Rode Rd, Chermside, Brisbane, Queensland 4032, Australia. E-mail: amy.spooner@health.qld.gov.au.
}

DOI: $10.4187 /$ respcare.02733 
instance, the use of computed tomography imaging exposes patients to substantial doses of ionizing radiation and cannot be performed at bedside. This requires transporting patients out of the ICU, posing safety risks to patients, and incurring considerable costs. ${ }^{11,12}$ An alternative to computed tomography imaging is the relatively new imaging method of electrical impedance tomography, which is a noninvasive, radiation-free monitoring tool that allows real-time imaging of ventilation at bedside. ${ }^{13,14}$ Electrical impedance tomography measures changes in lung volume and describes regional and global ventilation distribution. ${ }^{15}$ An electrode belt is placed around the patient's chest between the fourth and sixth intercostal spaces, and cross-sectional images of impedance distribution within a transverse slice of the thorax are generated. ${ }^{16}$ Electrical impedance tomography can identify and image spatial impedance changes associated with local air filling and emptying of the lungs, expressed as end-expiratory lung impedance (EELI). Previous studies have confirmed a linear relationship between EELI change and end-expiratory lung volume change. ${ }^{16-19}$ It is this relationship that allows EELI to be used as a surrogate measurement of end-expiratory lung volume.

The primary aim of this prospective observational study was to examine changes in end-expiratory lung volume in the supine position and at $20^{\circ}$ and $30^{\circ} \mathrm{HOBE}$ and to compare the changes in each position. Secondary aims were to map changes in end-expiratory lung volume over time (0-20 $\mathrm{min})$ and to examine the effect on oxygenation $\left(\mathrm{P}_{\mathrm{aO}} / \mathrm{F}_{\mathrm{IO}_{2}}\right)$, heart rate, and arterial blood pressure.

\section{Methods}

Ethical approval was obtained from the institutional human research and ethics committee (EC27105). This observational study was conducted at The Prince Charles Hospital, a tertiary hospital specializing in cardiothoracic surgery and a variety of medical and surgical emergencies.

\section{Study Population}

Written informed consent was obtained from patients preoperatively. Participants recruited to the study were postoperative cardiac surgery patients (18 y or older), hemodynamically stable postoperatively (ie, mean arterial pressure $>60 \mathrm{~mm} \mathrm{Hg}$, blood loss $<100 \mathrm{~mL}$ in the last $30 \mathrm{~min}$ ), had invasive blood pressure monitoring in situ, and were mechanically ventilated. Patients were excluded if they had open sternums or continuous air leak from cardiac drains.

\section{Electrical Impedance Tomography}

EELI measurements were performed with an evaluation kit (EIT Evaluation Kit 2, Dräger, Lübeck, Germany) that

\section{QUICK LOOK}

\section{Current knowledge}

Head of bed elevation (HOBE) is a commonly used therapeutic intervention in mechanically ventilated patients associated with a reduction in the incidence of ventilator-associated pneumonia. HOBE has also been shown to improve oxygenation and hemodynamic performance.

\section{What this paper contributes to our knowledge}

End-expiratory lung volume significantly increased with HOBE, and the change from $20^{\circ}$ to $30^{\circ}$ resulted in significant improvement in lung volumes. The use of $30^{\circ} \mathrm{HOBE}$ should be standard practice in the ICU, and supine positioning should be avoided.

had been calibrated and self-tested according to the manufacturer's instructions. Electrical impedance tomography files were automatically saved to the device's hard drive, downloaded as a Microsoft Excel spreadsheet, and analyzed by review software (v5.1, Dräger).

\section{Study Protocol}

Subjects were examined within $1 \mathrm{~h}$ of returning to the ICU from the operating theater. An electrode belt containing 16 equally spaced electrodes was placed around the subject's chest at intercostal spaces $4-6$. The first impedance measurement was conducted after $20 \mathrm{~min}$ in the supine position (baseline). Subjects were then placed at $20^{\circ}$ HOBE, and impedance measurements were conducted at $1,5,10$, and $20 \mathrm{~min}$ after the position change. The head of the bed was then raised to $30^{\circ}$, and measurements were repeated at the same time intervals. All electrical impedance tomography measurements were of 1-min duration. HOBE was measured using an angle indicator attached to the part of the bed that elevated. The angle indicator uses gravity to measure the degree of backrest elevation on a protractor, and its accuracy has been validated in a previous study. ${ }^{1}$

Subjects were sedated and ventilated in a synchronized intermittent mandatory ventilation volume control mode at a frequency of 10-12 breaths/min, PEEP $5 \mathrm{~cm} \mathrm{H}_{2} \mathrm{O}$, pressure support $10 \mathrm{~cm} \mathrm{H}_{2} \mathrm{O}$, peak flow $50 \mathrm{~L} / \mathrm{min}$, and tidal volume $6-8 \mathrm{~mL} / \mathrm{kg}$, in line with standard postoperative ventilator settings in our ICU. Subjects did not take spontaneous or assisted breaths during the study period. $\mathrm{F}_{\mathrm{IO}_{2}}$ was titrated according to subject requirements. Arterial blood gases (ABL800 gas analyzer, Radiometer Brønshøj, Denmark) were taken at baseline (supine position) and 10 
and 20 min (standard washout period in our ICU) after each position change, and $\mathrm{P}_{\mathrm{aO}_{2}} / \mathrm{F}_{\mathrm{IO}_{2}}$ was calculated. Heart rate and arterial blood pressure was measured at baseline and 1,10 , and $20 \mathrm{~min}$ after each position change. Additional data collected were subject demographics, body mass index, and surgical procedure.

\section{Statistical Analysis}

To show differences between HOBE over time, we plotted mean EELI at $20^{\circ}$ and $30^{\circ} \mathrm{HOBE}$, which were compared with the baseline. The mean paired difference $\left(20^{\circ}\right.$ minus $30^{\circ}$ ) for each subject and the overall mean difference were also plotted over time. The change in EELI over time was modeled using a mixed effect regression model to account for the non-independence of results from the same subject using a random subject intercept. $\operatorname{HOBE}\left(20^{\circ}\right.$ vs $30^{\circ}$ ) was the main predictor in this model, and EELI was the dependent variable.

The sample size of 20 was calculated based on a $20 \%$ difference in EELI in the $20^{\circ}$ versus $30^{\circ}$ group. To find this difference with $80 \%$ power using a $5 \%$ significance level required 20 subjects. This assumed that the paired difference in electrical impedance tomography $\left(20^{\circ}\right.$ minus $30^{\circ}$ ) had a normal distribution with an SD of $30 \%$. All analyses were performed using statistical software (R 2.14.1, R Foundation for Statistical Computing, Vienna, Austria).

\section{Results}

Forty patients were eligible for inclusion and were approached for written consent. Four refused consent due to apprehension of approaching surgery. Six patients were hemodynamically unstable postoperatively and were withdrawn, six patients had chest dressings that interfered with the application of the electrical impedance tomography belt, and four patients were cancelled for surgery.

Twenty subjects were examined, 15 of whom were males. No subjects required termination from the study due to adverse events associated with HOBE. The mean age of participants was $63 \pm 15 \mathrm{y}(\mathrm{SD})$, and the mean body mass index was $28 \pm 7 \mathrm{~kg} / \mathrm{m}^{2}$ (SD). Eleven subjects underwent coronary artery bypass graft surgery, 8 underwent valvular surgery, and one patient had mixed coronary artery bypass graft and valvular surgery (Table 1).

\section{Global EELI}

Significant increases in global EELI were seen with HOBE, with the greatest changes observed at 5 min after position change. Mean EELI increased by 1,054 impedance units at $20^{\circ}(95 \% \mathrm{CI} 888-1,219, P<.001)$ and by 1,327 impedance units at $30^{\circ}(95 \%$ CI $1,080-1,573$,
Table 1. Subject Demographics

\begin{tabular}{lc}
\hline \hline & Value \\
\hline Gender (male/female), $n$ & $15 / 5$ \\
Age (mean $\pm \mathrm{SD}), \mathrm{y}$ & $63 \pm 15$ \\
$\mathrm{BMI}($ mean $\pm \mathrm{SD}), \mathrm{kg} / \mathrm{m}^{2}$ & $28 \pm 7$ \\
Surgery, $n$ & \\
$\quad$ Coronary artery bypass graft & 11 \\
$\quad$ Valvular & 8 \\
Both & 1 \\
VC-SIMV settings* & \\
Frequency (range), breaths/min & $10-12$ \\
$\quad \mathrm{~F}_{\text {IO }}$ (range) & $0.4-0.8$ \\
PEEP, cm $\mathrm{H}_{2} \mathrm{O}$ & 5 \\
Pressure support, cm $\mathrm{H}_{2} \mathrm{O}$ & 10 \\
$\quad$ Flow, L/min & 50 \\
& \\
$n=20$ & \\
$*$ As per standard practice. & \\
BMI $=$ body mass index \\
VC-SIMV = synchronized intermittent mandatory ventilation with volume control ventilation \\
\hline
\end{tabular}

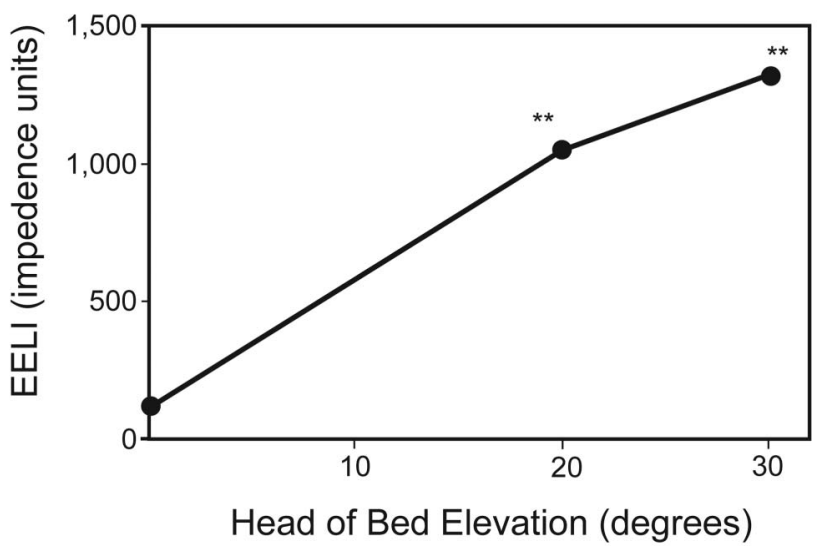

Fig. 1. Change from baseline in mean global end-expiratory lung impedance (EELI). The values displayed are maximum impedance measurements achieved at each head of bed elevation. ${ }^{\star \star} P<.001$.

$P<.001)$ from baseline. At the maximum impedance level reached in each position, EELI was 273 impedance units greater at $30^{\circ}$ compared with $20^{\circ} \mathrm{HOBE}(95 \% \mathrm{CI}$ 53-492, $P<.001)$. Figures 1 and 2 summarize these results.

\section{Left Versus Right EELI}

Increases were also seen in mean EELI in the left and right regions, with the greatest changes occurring at $5 \mathrm{~min}$ after position change. In the left region, mean EELI increased by 773 impedance units at $20^{\circ}$ (95\% CI 684-862, $P<.001)$ and by 1,007 impedance units at $30^{\circ}(95 \% \mathrm{CI}$ $880-1,134, P<.001)$ from baseline. At the maximum impedance level reached in each position, mean EELI was 


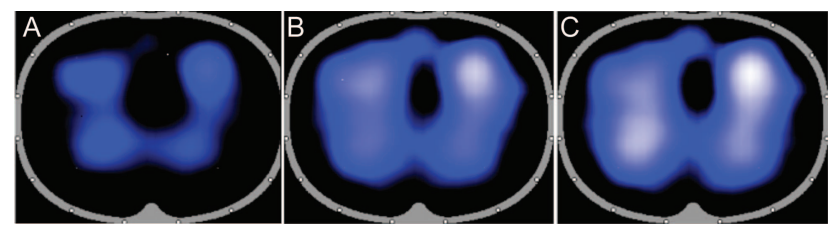

Fig. 2. Electrical impedance tomography of subject. 1. A: Subject is supine. B: Head of bed elevation (HOBE) $20^{\circ}$. C: HOBE $30^{\circ}$. Light blue to white color indicates the amount of volume in the lungs; this is an illustration of the air in the lungs increasing with increases in HOBE.

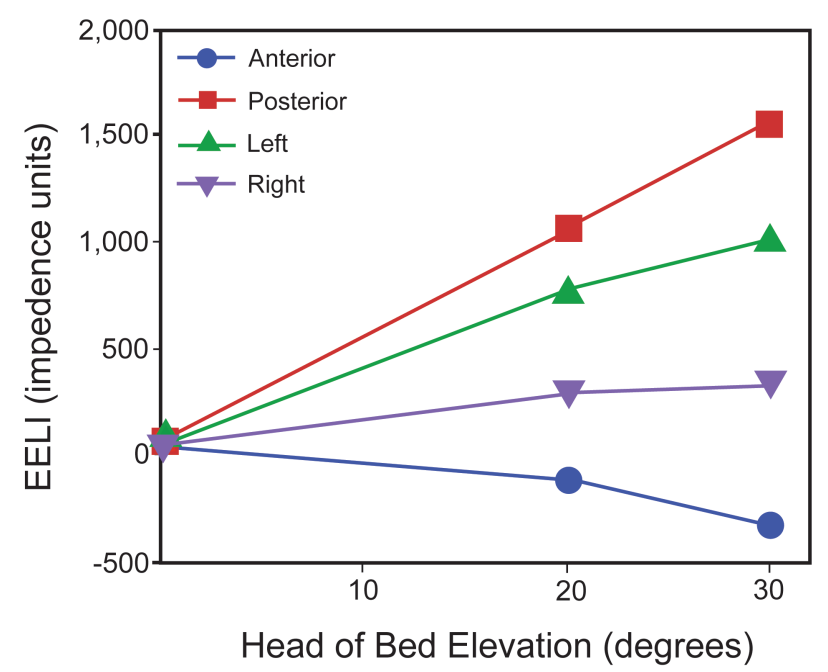

Fig. 3. Change from baseline in mean end-expiratory lung impedance (EELI) by lung region. The values displayed are maximum (for posterior, left, and right) and minimum (for anterior) impedance values achieved at each head of bed elevation (HOBE). $P<.001$ for all values at $20^{\circ}$ and $30^{\circ} \mathrm{HOBE}$.

234 impedance units higher at $30^{\circ}$ compared with $20^{\circ}$ (95\% CI 115-353, $P<.001$ ). Although still strongly significant, increases were not as dramatic in the right lung regions. Mean EELI increased by 280 impedance units at $20^{\circ}(95 \%$ CI $187-374, P<.001)$ and by 320 impedance units at $30^{\circ}(95 \%$ CI $188-451, P<.001)$ from baseline. At the maximum impedance level reached in each position, mean EELI was 40 impedance units greater at $30^{\circ}$ compared with $20^{\circ} \mathrm{HOBE}$ (95\% CI -78 to $158, P=.54$ ). Figures 2 and 3 summarize these results.

\section{Posterior Versus Anterior EELI}

Significant increases were seen in posterior EELI, with the greatest changes again seen $5 \mathrm{~min}$ after position change. Mean EELI increased by 1,056 impedance units at $20^{\circ}$ (95\% CI 944-1,168, $P<.001$ ) and by 1,544 impedance units at $30^{\circ}(95 \%$ CI $1,405-1,682, P<.001)$ from baseline. At the maximum impedance level reached in each position, EELI was 488 impedance units greater at $30^{\circ}$ compared with $20^{\circ}(95 \%$ CI $285-563, P<.001)$. In the anterior regions, however, decreases in EELI were seen as ventilation redistributed to the posterior regions. At $20^{\circ}$, the only significant change from baseline was a drop in mean EELI of -129 at $20 \mathrm{~min}$ at $20^{\circ}(95 \% \mathrm{CI}-230$ to $-28, P>.99$ ), and at $30^{\circ}$, the greatest decrease in mean EELI from baseline occurred at $1 \mathrm{~min}$ after position change ( -335 impedance units, $95 \% \mathrm{CI}-486$ to $-183, P<.001$ ). At the maximum decrease in impedance level in each position, decreases in EELI were greater at $30^{\circ}$ compared with $20^{\circ}$ (206 impedance units, 95\% CI -417 to -146 , $P<.001)$ as further redistribution of ventilation occurred. Figures 2 and 3 summarize these results.

\section{Change Over Time}

Increases were observed in EELI in the global, posterior, left, and right regions. When comparing impedance change between time points at both $20^{\circ}$ and $30^{\circ} \mathrm{HOBE}$, in all but one time point, statistically significant increases occurred between 1 and 5 min postposition change, with maximum ventilation achieved at $5 \mathrm{~min}$ in these positions. No significant changes in impedance were seen between the subsequent time points (5-10 and 10-20 min) (Table 2).

More variability in ventilation was observed in the anterior regions of the lung, where ventilation was seen to decrease with position change. When observing impedance change between time points at both $20^{\circ}$ and $30^{\circ}$ HOBE, the only statistically significant change was a decrease in EELI between 10 and $20 \mathrm{~min}$ at $20^{\circ} \mathrm{HOBE}$. However, there were no significant changes in impedance observed between the subsequent time points at $20^{\circ}$ and $30^{\circ}(1-5,5-10$, and $10-20 \mathrm{~min})$ in the anterior regions of the lung.

\section{Oxygenation and Hemodynamics}

Despite increases in EELI, there were reductions in $\mathrm{P}_{\mathrm{aO}_{2}} / \mathrm{F}_{\mathrm{IO}_{2}}$. This was statistically significant at only $20^{\circ}$ $\mathrm{HOBE}$, whereby $\mathrm{P}_{\mathrm{aO}} / \mathrm{F}_{\mathrm{IO}_{2}}$ fell by $46(95 \% \mathrm{CI}-81$ to -11 , $P=.01)$ from baseline. No statistically or clinically relevant changes in heart rate or arterial blood pressure were seen with HOBE (data not shown).

\section{Discussion}

This study demonstrated that HOBE improved end-expiratory lung volume in postoperative cardiac surgery subjects and that these improvements were more marked at $30^{\circ}$ HOBE. To the best of our knowledge, this is the first time the importance of HOBE has been confirmed with significant improvements in end-expiratory lung volume. These findings have important implications for clinical practice and demonstrate that patient positioning is a sim- 
Table 2. Change in EELI at Different Time Points by Head-of-Bed Angle

\begin{tabular}{|c|c|c|c|}
\hline EELI & $\begin{array}{l}\text { Head-of-Bed } \\
\text { Angle }\end{array}$ & $\begin{array}{l}\text { Time Point } \\
\text { (min) }\end{array}$ & $\begin{array}{c}\text { EELI Change } \\
\text { Over Time } \\
(95 \% \text { CI) }\end{array}$ \\
\hline \multirow[t]{6}{*}{ Global } & $20^{\circ}$ & $1-5$ & $356^{*}(185-526)$ \\
\hline & & $5-10$ & $-29(-195$ to 138$)$ \\
\hline & & $10-20$ & $-151(-312$ to 11$)$ \\
\hline & $30^{\circ}$ & $1-5$ & $301 \dagger(54-548)$ \\
\hline & & $5-10$ & $-229(-471$ to 13$)$ \\
\hline & & $10-20$ & $12(-227$ to 251$)$ \\
\hline \multirow[t]{6}{*}{ Left } & $20^{\circ}$ & $1-5$ & $237 *(143-330)$ \\
\hline & & $5-10$ & $10(-83$ to 102$)$ \\
\hline & & $10-20$ & $-85(-176$ to 6$)$ \\
\hline & $30^{\circ}$ & $1-5$ & $190 \dagger(64-316)$ \\
\hline & & $5-10$ & $-58(-182$ to 66$)$ \\
\hline & & $10-20$ & $17(-105$ to 140$)$ \\
\hline \multirow[t]{6}{*}{ Right } & $20^{\circ}$ & $1-5$ & $111 \dagger(9-213)$ \\
\hline & & $5-10$ & $47(-54$ to 148$)$ \\
\hline & & $10-20$ & $-59(-158$ to 40$)$ \\
\hline & $30^{\circ}$ & $1-5$ & $89(-41$ to 219$)$ \\
\hline & & $5-10$ & $-152 \dagger(-279$ to -24$)$ \\
\hline & & $10-20$ & $-5(-132$ to 121$)$ \\
\hline \multirow[t]{6}{*}{ Anterior } & $20^{\circ}$ & $1-5$ & $2(-111$ to 114$)$ \\
\hline & & $5-10$ & $122 \dagger(10-234)$ \\
\hline & & $10-20$ & $-194 *(-303$ to -85$)$ \\
\hline & $30^{\circ}$ & $1-5$ & 104 ( -45 to 254$)$ \\
\hline & & $5-10$ & -95 ( -243 to 52$)$ \\
\hline & & $10-20$ & $-3(-149$ to 143$)$ \\
\hline \multirow[t]{6}{*}{ Posterior } & $20^{\circ}$ & $1-5$ & $346 *(233-459)$ \\
\hline & & $5-10$ & $-65(-177$ to 47$)$ \\
\hline & & $10-20$ & $50(-60$ to 159$)$ \\
\hline & $30^{\circ}$ & $1-5$ & $174 \dagger(37-312)$ \\
\hline & & $5-10$ & $-115(-250$ to 20$)$ \\
\hline & & $10-20$ & $15(-119$ to 149$)$ \\
\hline \multicolumn{4}{|l|}{$* P<.001$} \\
\hline \multirow{2}{*}{\multicolumn{4}{|c|}{$\begin{array}{l}\dagger P<.05 \\
\text { EELI }=\text { enc }\end{array}$}} \\
\hline & lung imped & & \\
\hline
\end{tabular}

ple and effective method of optimizing functional residual capacity in a mechanically ventilated patient.

Global increases in end-expiratory lung volume were seen with $\mathrm{HOBE}$ at $20^{\circ}$ and $30^{\circ}$. This is particularly beneficial for the cohort studied because respiratory complications are common in patients undergoing general anesthesia. General anesthesia has been associated with an $\sim 20 \%$ reduction in functional residual capacity. ${ }^{20,21}$ This coupled with mechanical ventilation leads to pulmonary complications such as atelectasis and ventilation/perfusion mismatching..$^{20}$ Therefore, based on the global increases in end-expiratory lung volume observed in this study, HOBE may assist with preventing and/or reversing the complications associated with general anesthesia and mechanical ventilation.
The increases in end-expiratory lung volume seen with HOBE were greater in the left lung than in the right lung. These findings are particularly relevant because atelectasis and alveolar collapse occur in up to $90 \%$ of patients following cardiac surgery, $, 921,22$ with left-sided atelectasis more severe due to retraction of the left lower lobe during surgery. ${ }^{21}$ Furthermore, cardiac surgery patients who have internal mammary arteries harvested for coronary artery bypass grafts have worse pulmonary problems because of lung retraction. In our cohort, $75 \%$ of subjects undergoing coronary artery bypass grafts had internal mammary arteries harvested, predisposing them to further respiratory complications. These results confirm the assertion that sitting patients up significantly increases end-expiratory lung volume in both the left and right lungs and therefore could assist in reducing postoperative atelectasis and pulmonary complications commonly seen in cardiac surgery patients.

Significant improvements in ventilation of the posterior lung were seen with increasing HOBE. When the patient is in the supine position, the dependent posterior region has less ventilation. ${ }^{23}$ As the head of the bed is elevated, the posterior regions become less dependent, and ventilation is redistributed from anterior to posterior, which was evidenced by the observed reciprocal decreases in end-expiratory lung volume in the anterior region of the lung. ${ }^{23}$ These increases in end-expiratory lung volume in the posterior lung regions after HOBE could be seen to be protective against gravity-induced alveolar collapse and atelectasis, which are often observed in mechanically ventilated patients.

The greatest increases in end-expiratory lung volume were seen within 1-5 min after position change. This indicates that the beneficial effects of position change occur shortly after HOBE. Although small decreases in endexpiratory lung volume were seen at subsequent time points (10 and $20 \mathrm{~min}$ ), these were not statistically significant. The mechanism behind these reductions in end-expiratory lung volume is not clear, and it is not known when equilibration in end-expiratory lung volume is achieved after position change. Further research examining lung volume changes over time may assist in describing these decreases.

In our study, negligible changes in oxygenation were seen despite improvements in end-expiratory lung volume. This may be because of ventilation/perfusion mismatching. It is known that ventilation/perfusion ratios can worsen if aeration is improved to a region of lung with low perfusion $^{24}$ and that anatomical and functional lung recruitment of lung tissue can be partially dissociated..$^{9,24}$ Therefore, even with improvements in end-expiratory lung volume, $\mathrm{P}_{\mathrm{aO}} / \mathrm{F}_{\mathrm{IO}_{2}}$ may not be affected. Furthermore, previous work has shown that oxygenation may not be an accurate predictor of recruitment, as changes in gas exchange may be a reflection of changes in cardiac output. For instance, changes in cardiac output are known to sig- 
nificantly alter both venous and arterial saturations. ${ }^{12,25,26}$ Further research is required to determine whether $\mathrm{P}_{\mathrm{aO}_{2}} / \mathrm{F}_{\mathrm{IO}_{2}}$ changes over a longer period of time. Despite these findings, all subjects maintained peripheral oxygen saturation above $95 \%$ for the duration of the study.

Minimal changes in heart rate and arterial blood pressure were seen with HOBE. Similarly, de Laat et al ${ }^{10}$ found no significant influence on cardiac index in patients positioned at $30^{\circ}$ laterally compared with a supine position 2-4 h after surgery. Despite a small evidence base supporting the assertion, hemodynamic instability has been suggested as a contraindication for HOBE. ${ }^{27,28}$ Although it is clear that HOBE needs to be used with caution in certain hemodynamically unstable patients, our results indicate that it can be safely performed without hemodynamic compromise.

Based on current evidence, the Centers for Disease Control and Prevention guidelines recommend $30-45^{\circ}$ positions for all mechanically ventilated patients to prevent aspiration and respiratory complications associated with mechanical ventilation. ${ }^{29} \mathrm{~A}$ randomized trial demonstrated significant reductions in incidences of ICU-acquired pneumonia in patients positioned with HOBE compared with those in a supine position. In reality, compliance with these guidelines is rarely applied. This was confirmed in a multi-center trial conducted in ICUs in Australia and New Zealand that revealed the mean HOBE to be $23.8^{\circ}$, with our ICU at $19^{\circ} .{ }^{1}$ It was these findings that led us to compare $20^{\circ}$ (current practice) to $30^{\circ}$ (minimum Centers for Disease Control and Prevention recommendations) when examining end-expiratory lung volume in relation to HOBE. Although increases in end-expiratory lung volume were seen at $20^{\circ}$, our results clearly show a marked improvement at $30^{\circ} \mathrm{HOBE}$. Maintaining the minimum standard of $30^{\circ} \mathrm{HOBE}$ is clinically necessary if we are to reduce respiratory complications associated with mechanical ventilation and decrease mechanical ventilation times, as well as ICU and hospital stays.

Several studies support the use of HOBE in minimizing ventilator-acquired injuries such as ventilator-associated pneumonia and atelectasis, as well as improving oxygenation and lung recruitment for ARDS in mechanically ventilated patients. ${ }^{2,7,30}$ Torres et $\mathrm{a}^{31}$ demonstrated that the amount of radioactively tagged secretions retrieved through endobronchial aspiration increased as the time spent supine increased from 30 to $300 \mathrm{~min}$. Grap et al ${ }^{7}$ found that seriously ill patients who spent greater time at backrest elevations of $<30^{\circ}$ on the first day of intubation were more likely to develop ventilator-associated pneumonia, which further supports HOBE. These results show the importance of HOBE within the first $24 \mathrm{~h}$ of intubation to reduce ventilator-acquired pneumonia. The subjects in our study were examined within $1 \mathrm{~h}$ of arriving in the ICU from the operating theater. Before this, they had been in the supine position for $\sim 4-6 \mathrm{~h}$ for surgery. The mean $\mathrm{P}_{\mathrm{aO}_{2}} / \mathrm{F}_{\mathrm{IO}_{2}}$ in the cohort studied was $<300 \mathrm{~mm} \mathrm{Hg}$, indicating acute lung injury, which may be partially due to factors such as anesthesia, mechanical ventilation, cardiopulmonary bypass, and cardiac surgery. ${ }^{21,32}$ This highlights the importance of elevating the head of the bed immediately upon arrival to the ICU to assist in reducing the respiratory complications previously mentioned.

Although our study had a small sample size, statistically and clinically important improvements in end-expiratory lung volume were found. A stronger methodological design such as a randomized crossover study of HOBE instead of an observational study would have been useful, but this was a pragmatic study, and this approach would have lengthened the study duration and time spent in the supine position, thereby further prolonging ventilation times. Furthermore, although electrical impedance tomography generates an image from one cross section of the thorax, there is a strong correlation demonstrated previously between changes in EELI and changes in end-expiratory lung volume that allow reasonable conclusions to be ascertained from the data. This study investigated shortterm physiological responses to HOBE, and further research is required to measure the longer term outcomes.

\section{Conclusions}

This study demonstrates significant increases in endexpiratory lung volume associated with HOBE. Importantly, end-expiratory lung volume increases significantly between the measured current practice $\left(20^{\circ}\right)$ and the minimum HOBE recommended by the Centers for Disease Control and Prevention guidelines $\left(30^{\circ}\right)$, which may assist in reducing ventilator-acquired injuries. Thus, the use of $30^{\circ} \mathrm{HOBE}$ as a minimum in mechanically ventilated patients, unless contraindicated, should be standard practice in the ICU, and supine positioning should be avoided where possible. Further work is required to examine HOBE in relation to the wider ICU population and its long-term effects on oxygenation, ventilation times, and ICU and hospital stays.

\section{ACKNOWLEDGMENTS}

We thank Eckhard Teschnar (Dräger) for technical advice regarding the electrical impedance tomograph.

\section{REFERENCES}

1. Rose L, Baldwin I, Crawford T, Parke R. Semirecumbent positioning in ventilator-dependent patients: a multicenter, observational study. Am J Crit Care 2010;19(6):e100-e108.

2. Drakulovic MB, Torres A, Bauer TT, Nicolas JM, Nogué S, Ferrer M. Supine body position as a risk factor for nosocomial pneumonia in mechanically ventilated patients: a randomised trial. Lancet 1999; 354(9193):1851-1858. 


\section{Head-of-Bed Elevation Improves End-Expiratory Lung Volumes}

3. Goldhill DR, Imhoff M, McLean B, Waldmann C. Rotational bed therapy to prevent and treat respiratory complications: a review and meta-analysis. Am J Crit Care 2007;16(1):50-61.

4. Halpern NA, Pastores SM. Critical care medicine in the United States 2000-2005: an analysis of bed numbers, occupancy rates, payer mix, and costs. Crit Care Med 2010;38(1):65-71.

5. Rubenfeld GD, Caldwell E, Peabody E, Weaver J, Martin DP, Neff $\mathrm{M}$, et al. Incidence and outcomes of acute lung injury. N Engl J Med 2005;353(16):1685-1693.

6. Katz JD, Barash PG. Positional hypoxaemia following post-traumatic pulmonary insufficiency. Can Anaesth Soc J 1977;24(3):346352.

7. Grap MJ, Munro CL, Hummel RS 3rd, Elswick RK Jr, McKinney JL, Sessler CN. Effect of backrest elevation on the development of ventilator-associated pneumonia. Am J Crit Care 2005;14(4):325-332.

8. Banasik JL, Emerson RJ. Effect of lateral positions on tissue oxygenation in the critically ill. Heart Lung 2001;30(4):269-276.

9. Banasik JL, Emerson RJ. Effect of lateral position on arterial and venous blood gases in postoperative cardiac surgery patients. Am J Crit Care 1996;5(2):121-126.

10. de Laat E, Schoonhoven L, Grypdonck M, Verbeek A, de Graaf R, Pickkers P, van Achterberg T. Early postoperative 30 degrees lateral positioning after coronary artery surgery: influence on cardiac output. J Clin Nurs 2007;16(4):654-661.

11. Frerichs I, Hinz J, Herrmann P, Weisser G, Hahn G, Dudykevych T, et al. Detection of local lung air content by electrical impedance tomography compared with electron beam CT. J Appl Physiol 2002; 93(2):660-666.

12. Caruana LR, Paratz J, Chang AT, Fraser JF. Electrical impedance tomography in the clinical assessment of lung volumes following recruitment manoeuvres. Phys Ther Rev 2011;16(1):66-74.

13. Costa EL, Lima RG, Amato MB. Electrical impedance tomography. Curr Opin Crit Care 2009;15(1):18-24.

14. Corley A, Spooner AJ, Barnett AG, Caruana, LR, Hammond NE, Fraser JF. End-expiratory lung volume recovers more slowly after closed endotracheal suctioning than after open suctioning: a randomized crossover study. J Crit Care 2012;27(6):742.e1-742.e7

15. Zhao Z, Möller K, Steinmann D, Frerichs I, Guttmann J. Evaluation of an electrical impedance tomography-based Global Inhomogeneity Index for pulmonary ventilation distribution. Intensive Care Med 2009;35(11):1900-1906.

16. Hinz J, Hahn G, Neumann P, Sydow M, Mohrenweiser P, Hellige G, Burchardi H. End-expiratory lung impedance change enables bedside monitoring of end-expiratory lung volume change. Intensive Care Med 2003;29(1):37-43.

17. Harris ND, Suggett AJ, Barber DC, Brown BH. Applications of applied potential tomography (APT) in respiratory medicine. Clin Phys Physiol Meas 1987;8(Suppl A):155-165.
18. Hahn G, Sipinková I, Baisch F, Hellige G. Changes in the thoracic impedance distribution under different ventilatory conditions. Physiol Meas 1995;16(3 Suppl A):A161-A173.

19. van Genderingen HR, van Vught AJ, Jansen JR. Estimation of regional lung volume changes by electrical impedance pressures tomography during a pressure-volume maneuver. Intensive Care Med 2003;29(2):233-240.

20. Wahba RW. Perioperative functional residual capacity. Can J Anaesth 1991;38(3):384-400.

21. Matthay MA, Wiener-Kronish JP. Respiratory management after cardiac surgery. Chest 1989;95(2):424-434.

22. Corley A, Caruana LR, Barnett AG, Tronstad O, Fraser JF. Oxygen delivery through high-flow nasal cannulae increase end-expiratory lung volume and reduce respiratory rate in post-cardiac surgical patients. Br J Anaesth 2011;107(6):998-1004.

23. Rooney D, Friese M, Fraser JF, Dunster KR, Schibler A. Gravitydependent ventilation distribution in rats measured with electrical impedance tomography. Physiol Meas 2009;30(10):1075-1085.

24. Gattinoni L, Caironi P, Cressoni M, Chiumello D, Ranieri VM, Quintel M, et al. Lung recruitment in patients with the acute respiratory distress syndrome. N Engl J Med 2006;354(17):1775-1786.

25. Dantzker DR, Lynch JP, Weg JG. Depression of cardiac output is a mechanism of shunt reduction in the therapy of acute respiratory failure. Chest 1980;77(5):636-642.

26. Gattinoni L, Carlesso E, Brazzi L, Caironi P. Positive end-expiratory pressure. Curr Opin Crit Care 2010;16(1):39-44.

27. Winslow EH, Clark AP, White KM, Tyler DO. Effects of a lateral turn on mixed venous oxygen saturation and heart rate in critically ill adults. Heart Lung 1990;19(5 Pt 2):557-561.

28. Groden BM. Effect of posture on cardiac output after myocardial infarction. Br Heart J 1969;31(6):735-740.

29. Tablen OC, Anderson LJ, Besser R, Bridges C, Hajjeh R, CDC, Healthcare Infection Control Practices Advisory Committee. Guidelines for preventing of health-care-associated pneumonia, 2003: recommendations of the CDC and the Healthcare Infection Control Practices Advisory Committee. MMWR Recomm Rep 2004;53(RR3):1-36.

30. Zhu M, Zhang W, Wang JN, Yan H, Li YK, Ai B, et al. Upright position mechanical ventilation: an alternative strategy for ALI/ARDS patients? Med Hypotheses 2009;73(5):821-823.

31. Torres A, Serra-Batlles J, Ros E, Piera C, Puig de la Bellacasa J, Cobos A, et al. Pulmonary aspiration of gastric contents in patients receiving mechanical ventilation: the effect of body position. Ann Intern Med 1992;116(7):540-543.

32. Clark SC. Lung injury after cardiopulmonary bypass. Perfusion 2006; 21(4):225-228 